\title{
MODELLING OF A SOLAR WOOD DRYER WITH GLAZED WALLS
}

\author{
Naoual Bekkioui', André Zoulalian', Abdelillah Hakam ${ }^{1}$, Farida Bentayeb ${ }^{2}$, Abdessadek Sesbou ${ }^{4}$
}

\begin{abstract}
This work present a study of a solar wood dryer in a Moroccan climate. The wood drying process is investigated theoretically by a mathematical model based on actual climate data. The model constantly gives dryer humidity and temperatures (air and walls) as well as wood temperature and moisture contents. For verification, the present drying model is executed within the simulation program with experimental data of wood drying experiments conducted in two dryers located in two different sites. The computational results show a reasonable agreement between the predicted and measured wood moisture content.
\end{abstract}

Key words: Solar dryer, Modelling, Wood, Temperature, Moisture content

\section{RESUMEN}

Este trabajo presenta un estudio de un secador solar de madera en un clima marroquí. El proceso de secado de madera es investigado teóricamente desarrollando un modelo matemático basado en datos climáticos reales. El modelo da a cada momento, la humedad y la temperatura del secador (aire y paredes) así como la temperatura y la humedad de la madera. Para la verificación experimental, este modelo de secado es introducido en el programa de simulación con datos experimentales de secado de madera de los experimentos realizados en dos secaderos situados en dos lugares diferentes. Los resultados muestran un acuerdo razonable entre la humedad de la madera predicha y medida experimentalmente.

Palabras Clave: Secador solar, Modelización, Madera, Temperatura, Humedad.

\footnotetext{
${ }^{1}$ Laboratoire des Sciences et Technologie du Bois, Faculté des Sciences, 4 Avenue Ibn Battouta B.P. 1014 Rabat, Maroc

${ }^{2}$ LERMAB- Université de Nancy 1, BP 239 - 54560 Vandoeuvre les Nancy, France

${ }^{3}$ Département de Physique, Faculté des Sciences, 4 Avenue Ibn Battouta B.P. 1014 Rabat, Maroc

${ }^{4}$ Ecole Nationale Forestière d'Ingénieurs (ENFI), BP: 511 - 11000 Salé, Maroc

Corresponding author: andre.zoulalian@lermab.uhp-nancy.fr

Received : 15.06.2009. Accepted: 02.10.2009.
} 


\section{INTRODUCTION}

The drying of wood is an important step in the wood processing industry. Indeed, it is necessary to remove the moisture content of wood to a certain level for improving its quality before it can be manufactured into finished end products.

In the past few decades, considerable work has been done on the development of drying processes and has been conducted into the use of solar dryers for wood drying. These dryers can be divided into two categories: greenhouse type solar dryers and solar dryers with external collectors. Research studies around the world have shown that solar dryers give a reasonable technical economical performance which justifies their feasibility in many countries. A low cost solar dryer was designed and built from readily available materials in USA (Chen and Helton, 1989). The dryer offered an energy efficient and economically attractive method to dry wood. The dried wood quality was excellent and the drying effects were minimal. A greenhouse tunnel dryer was built in Argentina (Reuss et al. 1997). The results gained from the project confirmed the advantages of solar wood drying. The drying time was much shorter than with open air drying. Damage of the wood during drying could be avoided and operating costs were low since neither special control equipment nor fuel was necessary.

Modelling of the wood drying is important for solar dryers design to improve their performance and efficiency, optimize their dimensions and to predict the drying process. Many mathematical models have been proposed to describe the operation of solar dryers. Taylor and Weir (1985), Haque and Langrish (2003), Awadallah et al. (2004), Khater et al. (2004) and Helwa et al. (2004) proposed all different drying models based on the most common heat and mass transfer operations. They investigated numerically and experimentally the drying process. Their studies show, generally, reasonable agreement between predicted and experimental results.

In Morocco, the artisanal sector using wood material is facing serious problems related to the quality and artistic finishing of its products. To provide a scientific way for the artisans to build their small dryers while consuming as little energy as possible, Bentayeb et al. (2008) have developed a first mathematical approach that considers a single average temperature of a greenhouse wood dryer to study numerically the dryer behaviour in a Moroccan climate. Nevertheless, no comparison between simulated results and experimental measurements has been shown in their study.

In the present work, we develop a second approach that considers for each element of the dryer its own temperature. The calculations are carried out to dry $1,5 \mathrm{~m}^{3}$ of thuya (Tetraclinis articulata Vahl), resinous wood using in decoration and joinery in Morocco, from an initial moisture content equal to $35 \%$ to a final moisture content equal to $15 \%$. A comparative study is established to validate the mathematical modelling by applying the model to the data of two drying cycles performed for two wood species in two different Moroccan climates (Casablanca: $33^{\circ} 32^{\prime} \mathrm{N}, 7^{\circ} 41^{\prime} \mathrm{W}$ and Essaouira: $31^{\circ} 31^{\prime} \mathrm{N}, 9^{\circ} 47^{\prime} \mathrm{W}$ ).

\section{MATERIALS AND METHODS}

\section{Solar dryer design}

The dryer studied is a greenhouse solar wood dryer (Fig.1), same type of dryers used in experimental works carried out in Morocco (Youssefi 1997, Elkannafi 2002). The dryer is a thermodynamic system where the air is the drying agent. The roof is south facing at a slope equal to 25 degrees from the horizontal. This inclination allows better optimization of the incoming solar radiation while minimizing the inside volume unusable for stacking wood. The solar radiation is transmitted inside the dryer by single glazing walls (east, west and south) and the sloping roof (6mm thick glass). 
On the north insulated wall, there is a door to admit the wood load. The floor is well insulated to reduce the heat losses. It is made of two layers of cork $(0.033 \mathrm{~m})$ and polystyrene $(0.002 \mathrm{~m})$ laid between a layer of concrete $(0.12 \mathrm{~m})$ and a layer of cement $(0.045 \mathrm{~m})$. An electric fan is placed above the wood stack to ensure better uniformity of air. The flow rate supplying the dryer is $1.2 \mathrm{~m} / \mathrm{s}$, which corresponds to an average air velocity inside the dryer of $1 \mathrm{~m} / \mathrm{s}$. The evacuation of the humid air towards the outside is manually operated from 10 am to $4 \mathrm{pm}$ through closeable vents perforated on the northern wall.

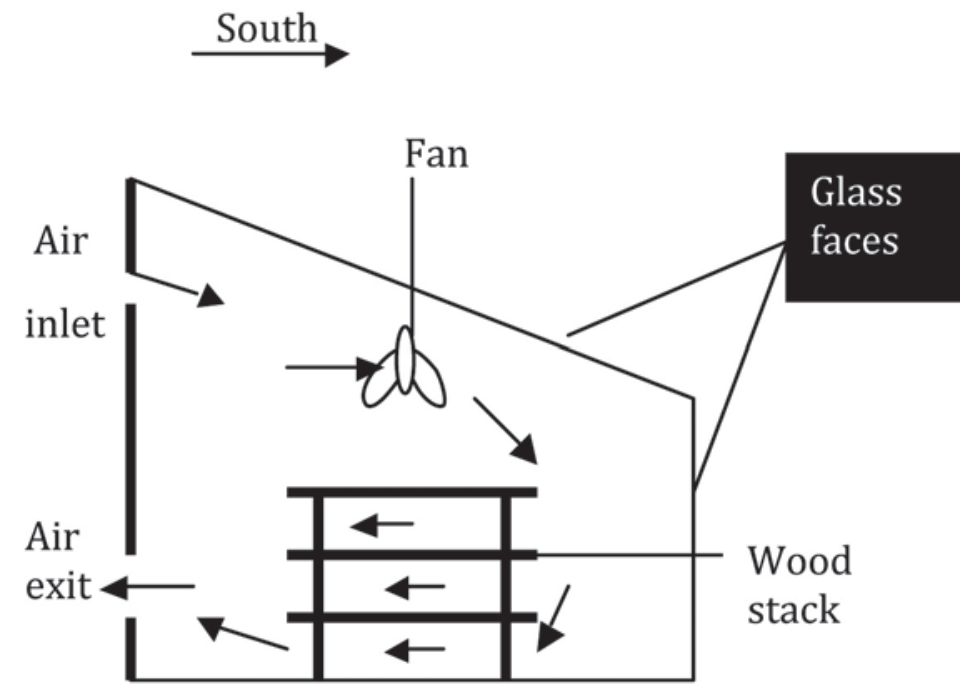

Fig.1. Schematic representation of the solar wood dryer

\section{Climatic data}

The climatic data using in the simulation are those of the city of Rabat, coastal city of latitude 34 degrees north and longitude 7 degrees west. The solar data and the climatic variables relating to the year 2002 were provided to us by the Laboratory of Solar energy of Mohammed V- Agdal University, Rabat. According to the data available and by applying relations that give the total radiation on a sloped plane, we have calculated the solar energy received by the north face and by each transparent face of the dryer, namely: the sloped roof, the vertical southern face, the eastern face and the western face (see Appendix).

\section{Modeling of the Dryer}

\section{Model Hypotheses}

- The circulation of moist air in the dryer allows us to assume that the dryer is a homogeneous system at the level of its different components.

- We limit the absorption of solar radiation to the glass, the north wall and the gas. On the other hand, we assume that there is no direct radiation on the wood stack because the moist air absorbs thermal radiation. 
- We consider a direct radiative exchange between the glazing, the wood stack and the gas phase and between the north wall, the wood stack and the gas phase. On the other hand, we neglect the radiative exchanges between the glazing and the north wall insofar as between them there is the wood stack and the gas phase.

\section{Model Equations}

The moisture content of the wood or air is expressed as a ratio of the mass of water contained in the wood or air to the mass of the oven-dried wood or dry air. So for wood, the moisture content $X$ $(\mathrm{kg} / \mathrm{kg})$ is computed as follows:

$$
X=\frac{M-M_{0}}{M_{0}}
$$

The analysis of the dryer is based on writing the mass balances and energy balances

\section{a) Mass Balances}

\section{- Mass balance of water in the solid phase (wood)}

The transfer of water within the wood (moisture content less than 50\%) can be reduced to a purely diffusive transfer. The mass balance of water in the solid phase can be written:

$$
M_{0} \frac{d X}{d t}=-K_{e} S_{b}\left(X-X^{*}\right)
$$

$X^{*}$ is the moisture content of the wood in equilibrium with the moisture content of the surrounding air.

$K_{e}$ is a global mass transfer coefficient that integrates transfers within and on the surface of wood. $K_{e}$ may be expressed as a function of the partial mass transfer coefficient in the solid phase and the partial mass transfer coefficient in the gas phase (Chrusciel et al. 1999):

$$
\begin{gathered}
\frac{1}{K_{e}}=a_{0} \cdot \exp \left(\frac{c_{0}}{T_{a}}\right) \cdot e+b_{0} \cdot \exp \left(\frac{c_{0}}{T_{a}}\right) \cdot v^{-p} \cdot \exp \left(-\frac{z}{X_{F S P}-X^{*}}\right) \\
a_{0}=0,2265 ; \quad b_{0}=268,9 ; \quad c_{0}=2543,6 \quad p=2,7158 ; \quad \mathrm{z}=1-\frac{H R}{100}
\end{gathered}
$$

$X_{F S P}$ is the wood moisture content at the fiber saturation point $\left(X_{F S P}=0.3\right)$

- Global mass balance of water in the gas phase

The global mass balance of water in the dryer is given by:

$$
G\left(W_{S}-W_{E}\right)+m_{a} \frac{d W_{S}}{d t}+M_{0} \frac{d X}{d t}=0
$$

$m_{a}$ is the mass of dry air in the dryer, assumed constant. 


\section{b) Energy Balance}

\section{- Energy balance of glazing}

The thermal energy accumulated on a glass $v i$ of area $S_{v i}$ and mass $m_{v i}$ is given as the sum of the heat absorbed by the glass from solar radiation, convective-radiation heat exchanged with the air inside the dryer, the convective-radiation heat exchanged with the ambient air, radiation heat exchanged with the wood stack. Evaluating the terms gives, for the energy balance of the glass $v i$ :

$$
\begin{aligned}
& m_{v i} C_{v i} \frac{d T_{v i}}{d t}=\alpha_{v i} S_{v i} G_{v i}+K_{v i}^{*} S_{v i}\left(T_{a}-T_{v i}\right)+ \\
& k_{v i} S_{v i}\left(T_{e x}-T_{v i}\right)+\sigma S_{v i} F_{i b}\left(T_{b}^{4}-T_{v i}^{4}\right)
\end{aligned}
$$

The coefficient $K_{v i}^{*}$ includes convective and radiation exchanges between the gas and the glass $v i$.

Equation (5) is applied to the different glazing, namely: southern sloped glass (v1), southern vertical glass (v2), eastern glass (v3) and western glass (v4).

\section{- Energy balance of the Northern wall}

The energy balance of the north wall of mass $m_{N}$ and area $S_{N}$ is given by:

$$
\begin{aligned}
& m_{N} C_{N} \frac{d T_{N}}{d t}=\alpha_{N} S_{N} G_{N}+K_{N}^{*} S_{N}\left(T_{a}-T_{N}\right) \\
& +k_{N} S_{N}\left(T_{e x}-T_{N}\right)+\sigma S_{N} F_{b N}\left(T_{b}^{4}-T_{N}^{4}\right)
\end{aligned}
$$

\section{- Energy balance of the wood stack}

The wood stack is composed of the oven dry mass $M_{0}$ and liquid water or adsorbed water of $\operatorname{mass} M-M_{0}=X M_{0}$.

The energy balance of the wood stack is given by:

$$
\begin{aligned}
& -M_{0} \frac{d X}{d t} \Lambda+M_{0}\left(C_{b}+X C_{e}\right) \frac{d T_{b}}{d t}= \\
& K_{b}^{*} S_{b}\left(T_{a}-T_{b}\right)+\sigma S_{N} F_{N b}\left(T_{N}^{4}-T_{b}^{4}\right)+ \\
& \sum_{i} \sigma S_{v i} F_{i b}\left(T_{v i}^{4}-T_{b}^{4}\right)
\end{aligned}
$$


- Energy balance of the gas phase

The energy balance of the air inside the dryer is given by:

$$
\begin{aligned}
& m_{a} C_{a} \frac{d T_{a}}{d t}=\sum_{i}\left(1-\alpha_{i}\right) S_{v i} G_{v i}+\sum_{i} K_{v i}^{*} S_{v i}\left(T_{v i}-T_{a}\right)+ \\
& K_{N}^{*} S_{N}\left(T_{N}-T_{a}\right)+K_{b}^{*} S_{b}\left(T_{b}-T_{a}\right)+G C_{a}\left(T_{E}-T_{a}\right)+ \\
& G \Lambda\left(W_{E}-W_{S}\right)
\end{aligned}
$$

$T_{E}$ is the temperature of air entering dryer and is equal to the ambient air temperature $\left(T_{e x}\right)$ because the dryer is considered a direct solar dryer.

\section{Simulation of the Dryer}

The working of the wood dryer is described by a system composed of six first order differential equations - (2), (4), (5), (6), (7), (8) - and a function $f$ expressing the equilibrium between water in wood and water in the gas phase, $X^{*}=f\left(W_{S}, T_{d}\right)$.

Known data: $G_{v i} G, W_{E}, T_{E}, m_{a^{\prime}}, M_{0}, X_{0}$

\begin{tabular}{|c|c|}
\hline \multicolumn{2}{|c|}{ Drying air } \\
\hline$v$ & $1 \mathrm{~m} / \mathrm{s}$ \\
\hline$\rho_{\mathrm{g}}$ & $1,41 \mathrm{~kg} \cdot \mathrm{m}^{-3}$ \\
\hline vent section & $0.02 \mathrm{~m} \times 0.02 \mathrm{~m}$ \\
\hline$G$ & $0.05 \mathrm{~kg} \cdot \mathrm{s}^{-1}$ \\
\hline$m_{a}$ & $12,7 \mathrm{~kg}$ \\
\hline \multicolumn{2}{|c|}{ Wood } \\
\hline$X_{0}$ & $0.35 \mathrm{~kg} / \mathrm{kg}$ \\
\hline$\rho_{0}$ & $520 \mathrm{~kg} \cdot \mathrm{m}^{-3}$ \\
\hline$V_{b}$ & $1.5 \mathrm{~m}^{3}$ \\
\hline$M_{0}$ & $778 \mathrm{~kg}$ \\
\hline \multicolumn{2}{|c|}{ Climatic data (Appendix) } \\
\hline $\begin{array}{l}T_{E}=T_{e x} \\
W_{E}=W_{E}\left(H R, T_{E}\right) \\
G_{v i}=\mathrm{I}_{\beta}\end{array}$ & \\
\hline
\end{tabular}

Unknown data: $W_{S^{\prime}} X, X^{*}, T_{a^{\prime}}, T_{b^{\prime}}, T_{v i^{\prime}} T_{N}$

Table 1: Drying air, wood and climatic data for the simulated process 


\section{Evaluation of $f$, Geometrical Factors and Transfer Coefficients}

- The relation that has allowed us to obtain the values of $X^{*}$ that correspond as closely as possible to those given in the literature is the following (Simpson and TenWolde, 1999):

$$
X^{*}=\frac{18}{A}\left[\frac{C H r}{1-C H r}+\frac{C_{1} C H r+2 C_{1} C_{2} C^{2} H r^{2}}{1+C_{1} C H r+C_{1} C_{2} C^{2} H r^{2}}\right]
$$

where:

$A=330+0.452 T_{a}+0.00415 T_{a}^{2}$

$C=0.791+0.000463 T_{a}-0.000000844 T_{a}^{2}$

$C_{1}=6.34+0.000775 T_{a}-0.0000935 T_{a}^{2}$

$C_{2}=1.09+0.0284 T_{a}-0.0000904 T_{a}^{2}$

$T_{a}=$ Temperature $\left({ }^{\circ} \mathrm{F}\right)=\left(\right.$ Temperature $\left.\left({ }^{\circ} \mathrm{C}\right) \times 9 / 5\right)+32$.

$H r=$ relative humidity $/ 100$

- Geometrical factors $F_{b v}$ and $F_{b N}$ are evaluated using the method given by Mac Adams (1964).

For the geometry of the wood stack with $L_{p}=2 \mathrm{~m}, l_{p}=1 \mathrm{~m}, h_{p}=1,4 \mathrm{~m}$ and using the values $\varepsilon_{b}=0.93, \varepsilon_{v}=0.90$ and $\varepsilon_{N}=0.22$, the values obtained for the geometric factors are :

$$
F_{b N}=0.075, F_{b v}=0.72 \text { then } F_{b v i}=0.18 \text {. }
$$

- Let us assume that the heat transfer coefficients for the various surfaces are identical.

The convective-radiation heat transfer coefficient between the glass, the north wall and the ambient air was obtained by running the simulation program with values between 6 and $10 \mathrm{~W} / \mathrm{m}^{2} /{ }^{\circ} \mathrm{K}$, choosing the value which gave a simulated result closest to the experimental ones. This gave $k=8 \mathrm{~W} /$ $\mathrm{m}^{2} /{ }^{\circ} \mathrm{K}$.

\section{Numerical method}

Equations (2), (5), (6), (7) and (8) were solved numerically using a fourth order Runge Kutta method (Nougier 1989). 
Equation (4) was solved using the finite elements method. If $W_{S, t_{0}}$ is the value of $W_{S}$ at time $\mathrm{t}_{0}$, its value at time $t_{1}=t_{0}+\Delta t$ is given by:

$$
W_{S, t_{1}}=\frac{m_{a} W_{S, t_{0}}+G \Delta t W_{E, t_{1}}+M_{0}\left(X_{t_{0}}-X_{t_{1}}\right)}{G \Delta t+m_{a}}
$$

The calculations were marched forward in steps of $\Delta t=1$ minute, stored and recorded every hour. All computations were done using aTurbo Pascal Program.

\section{RESULTS AND DISCUSSION}

\section{Drying Curve}

In this section, we are interested in the time taken by $1.5 \mathrm{~m}^{3}$ of thuya (Tetraclinis articulata Vahl) to dry from a moisture content $X=0.35$ to a moisture content $X=0.15$.

Figure 2 presents predicted moisture content evolution for $27 \mathrm{~mm}$ thick boards of thuya. It is shown that to dry the wood from $35 \%$ to $15 \%$, a period of 366 hours is necessary. The initial drying time 0 corresponds to 6 a.m., local time in Rabat.

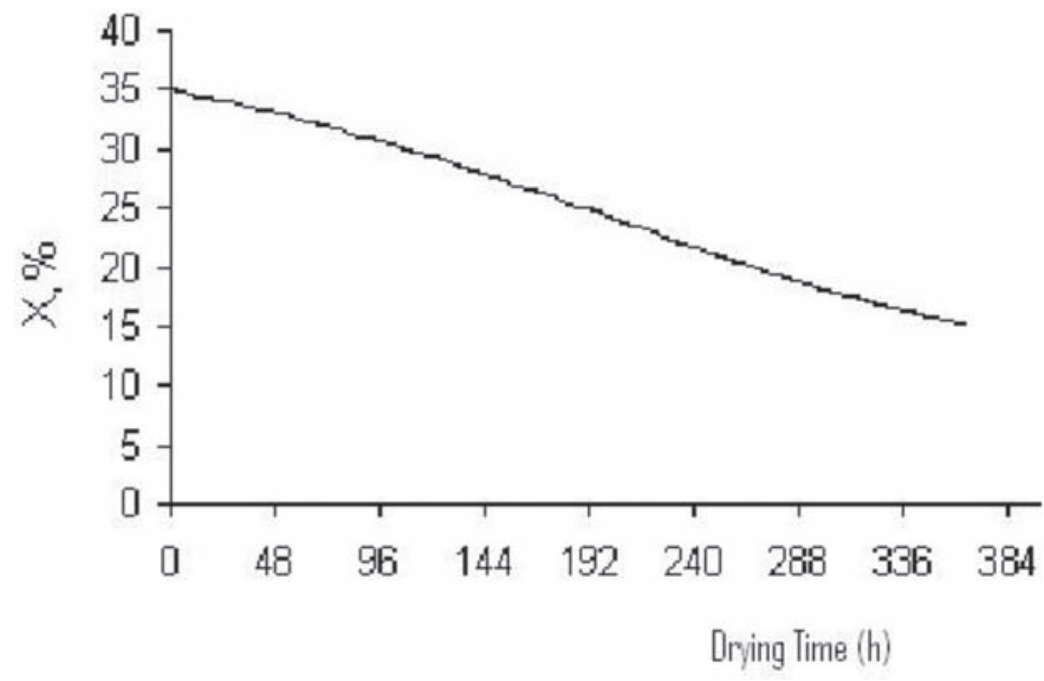

Fig.2. Predicted moisture content for $27 \mathrm{~mm}$ thick boards of thuya

\section{Temperatures of the Different Faces of the Dryer}

Figure 3 shows the time variations of the temperatures relative to the northern face $T_{N}$, the sloping roof $T_{v 1}$, the vertical southern face $T_{v 2}$, the eastern face $T_{v 3}$ and the western face $T_{v 4}$. The curves are similar and follow systematically the solar radiation variation.

Also from Figure 3, we notice that the temperature of the northern wall exceeds at a certain moment the other temperatures. This could be due to an overestimation of this temperature by our theoretical model, which ignores the effects of shadows. 


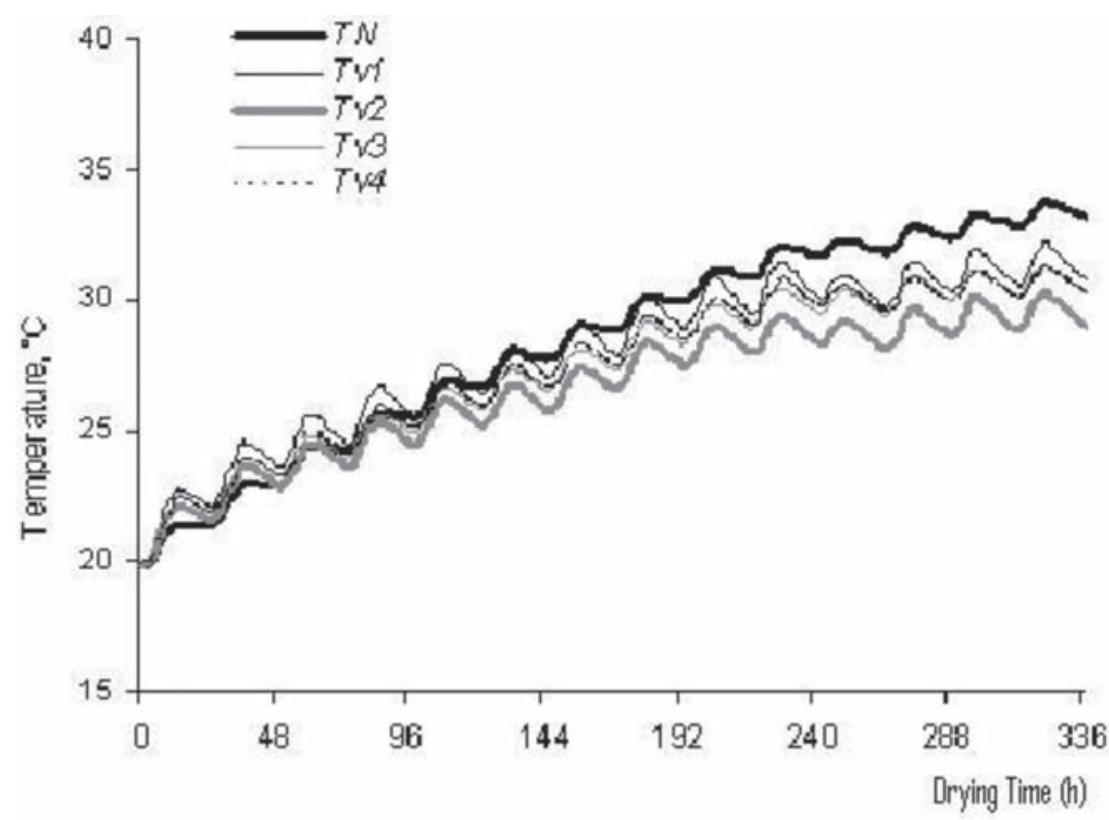

Fig.3. Temperature profiles of the different faces of the dryer

\section{Air and wood temperature}

The curves in Figure 4 give the time variation of the predicted air temperature $T_{a}$ and the wood temperature $T_{b}$. As shown by the figure, both temperatures rise throughout the drying process. $T_{a}$ follows the solar radiation variation. However, we note the absence of fluctuations for $T_{b}$, which shows its steady variation during through time. The same figure displays the measured ambient air temperature $T_{e x}$. It is clear that the wood temperature, as well as the maximum and minimum air temperatures inside the dryer, are always higher than those of the ambient air, which shows the importance of the thermal balance of the solar dryer.

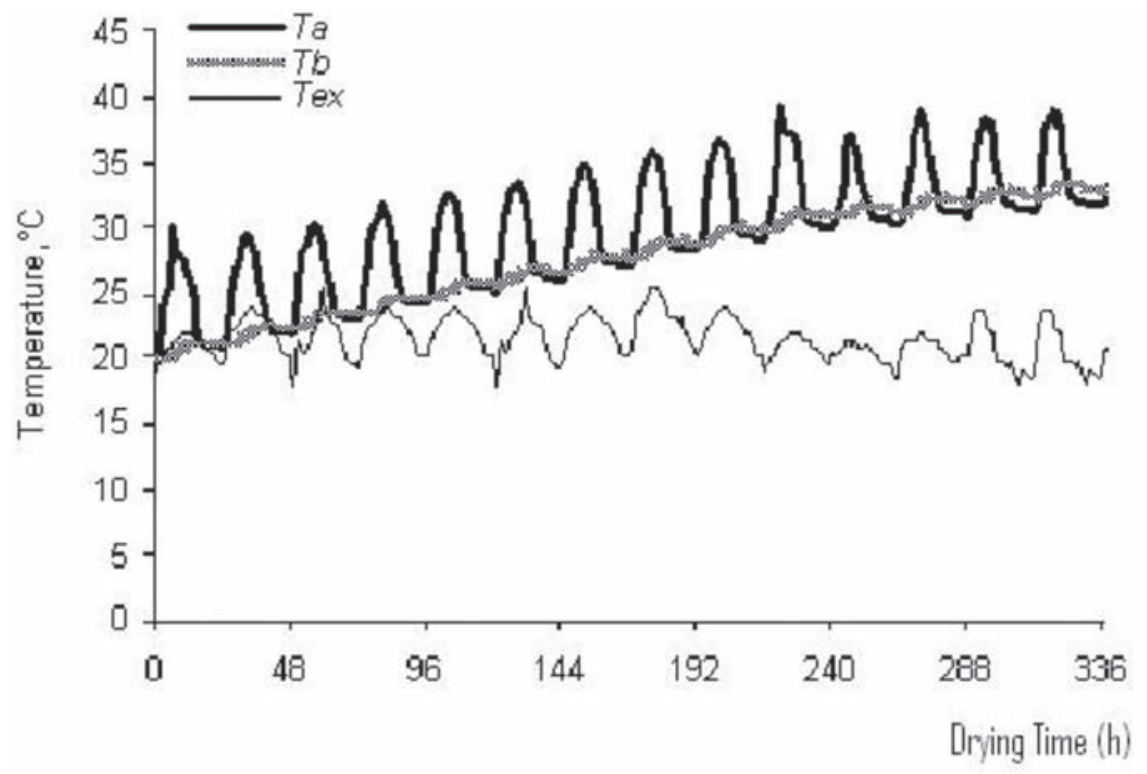

Fig.4. Time evolution of the temperature inside and outside the dryer 


\section{Air Humidity Variation inside the Dryer}

Figure 5 presents the time variation of the air moisture content $W_{s}\left(\mathrm{~g} / \mathrm{kg}\right.$ dry air). $W_{s}$ values vary daily between a minimum of about $13 \mathrm{~g} / \mathrm{kg}$ and a maximum of about $18 \mathrm{~g} / \mathrm{kg}$. These values tend to decrease towards the end of the drying because of the decrease of water derived from the wood.

To show the influence of the air temperature $T_{a}$ on the air humidity variation in the dryer, we have represented in Figure 6 the variation of the air's relative humidity $\mathrm{RH} \%$ and the temperature $T_{a}$. We may conclude that $R H$ and $T_{a}$ vary in opposite ways. The increase of air temperature at the beginning of the day leads to a decrease of the air's relative humidity, which reaches its minimum when the temperature is at its maximum value. In the afternoon, when solar radiation diminishes so does $T_{a}$ decrease and therefore allows the $\mathrm{RH}$ to increase progressively and reach its maximum value.

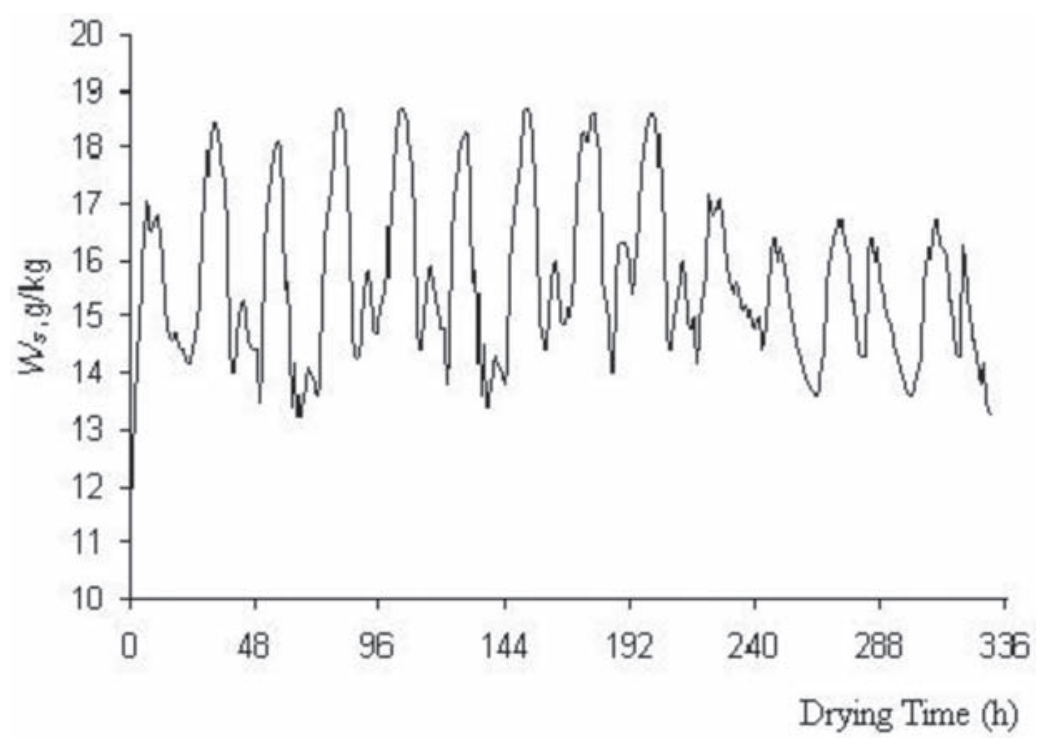

Fig.5. Air moisture content profile inside the dryer

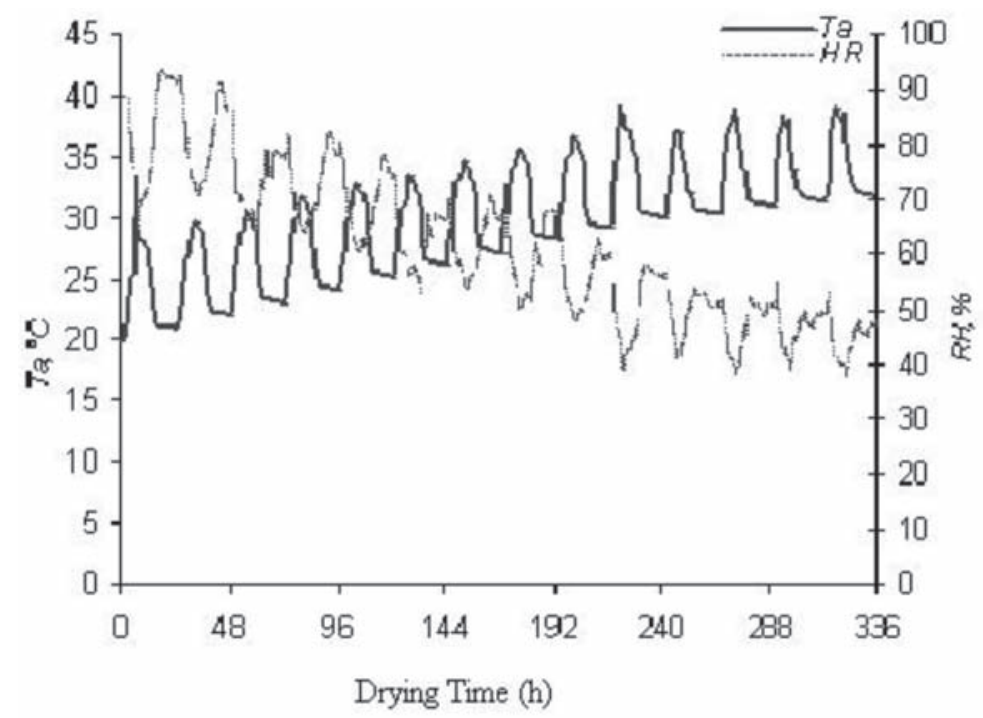

Fig.6. Predicted air temperature and relative humidity inside the dryer 


\section{Comparison of Experimental Results and Computed Ones}

To test the validity of the developed model, we have applied it to the data relating to two experiments carried out on greenhouse solar dryers located in two different sites.

The first experiment took place in June 1997 in Casablanca, coastal city near Rabat and whose climatic conditions are similar to that of Rabat (Youssefi 1997). The second experiment was performed between May 26 and June 17, 2002 in Essaouira, coastal city located in the south of Casablanca (Elkannafi 2002). Table 2 represents the characteristics related to each drying cycle.

Table 2. Characteristics of the drying cycles performed in Casablanca and Essaouirra

\begin{tabular}{|c|c|c|c|c|c|c|c|}
\hline Experiment & Wood species & $\begin{array}{c}\text { Wood thickness } \\
(\mathrm{mm})\end{array}$ & $\begin{array}{c}\text { Wood density } \\
\left(\mathrm{kg} \cdot \mathrm{m}^{-3}\right)\end{array}$ & $\begin{array}{c}\text { Wood volume } \\
\left(\mathrm{m}^{3}\right)\end{array}$ & $\begin{array}{c}\text { Fill factor } \\
\left(V_{b} / V\right)\end{array}$ & $S_{b}\left(\mathrm{~m}^{2}\right)$ & $\begin{array}{c}\text { Air velocity } \\
\left(\mathrm{m}_{\mathrm{s}} \mathrm{s}^{-1}\right)\end{array}$ \\
\hline Casablanca & Pine & 27 & 450 & 1 & 0.14 & 44 & 1 \\
\hline Essaouira & Thuya & 27 & 520 & 0.4 & 0.06 & 28 & 0.5 \\
\hline
\end{tabular}

To establish the comparison, we have introduced in the simulation program the characteristics of each wood (pine in Casablanca and thuya in Essaouira) as well as the size of the stacks and dryers, while keeping climatic data relating to Rabat. Finally, for both experiments, the dryer is supposed to be opened from 10 am to $4 \mathrm{pm}$. Otherwise, it is kept closed.

The comparative study between computed and experimental values of wood moisture content $X$ for the two species in the two cities (Figures 7 and 8 ) shows a satisfactory agreement between theory and experiment. We note that experimental data relative for Casablanca is missing between the 6th and 10th day, but for the other days the comparison reflects a very interesting agreement with a relative difference of less than $2 \%$. For the city of Essaouira, the gap between the two curves is around $14 \%$. We can observe that with the climatic data of Rabat, the modelling of the dryer located in Casablanca showed a maximum drying time rate at the $11^{\text {th }}$ day, but in the case of Essaouira, the maximum drying time rate obtained experimentally is observed right at the beginning of the drying cycle. These differences are probably due to sunlight conditions, since Essaouira is situated south of Rabat and Casablanca, we can assume that it must be sunnier, but this point should be validated by studying the influence of the sunlight conditions on the modelling of drying.

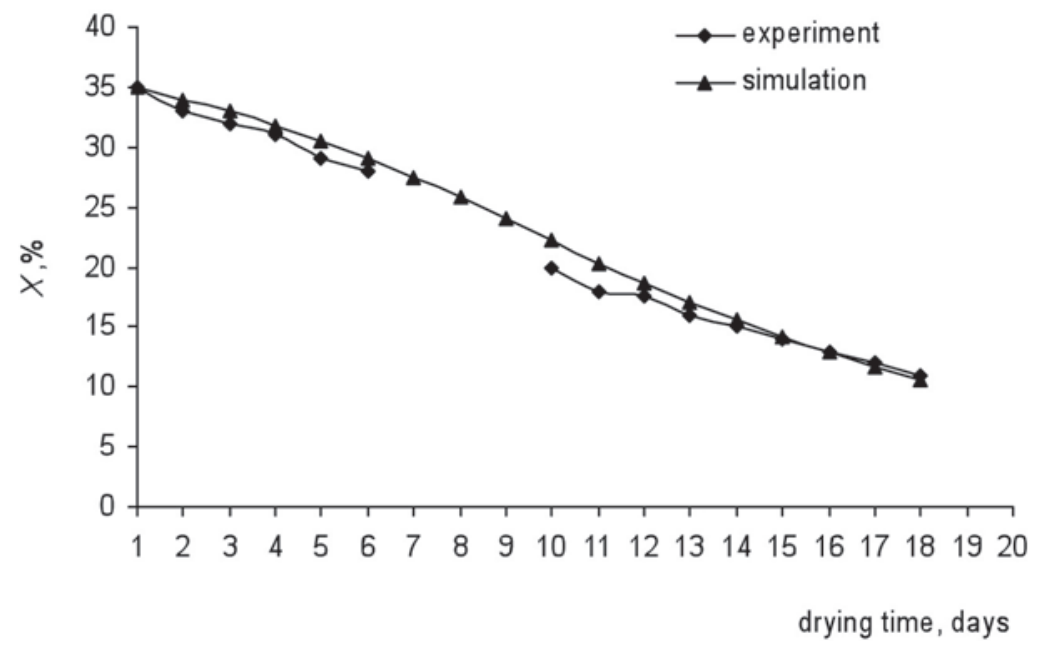

Fig.7. Comparison of measured and computed moisture content of solar drying for $27 \mathrm{~mm}$ of pine in Casablanca 


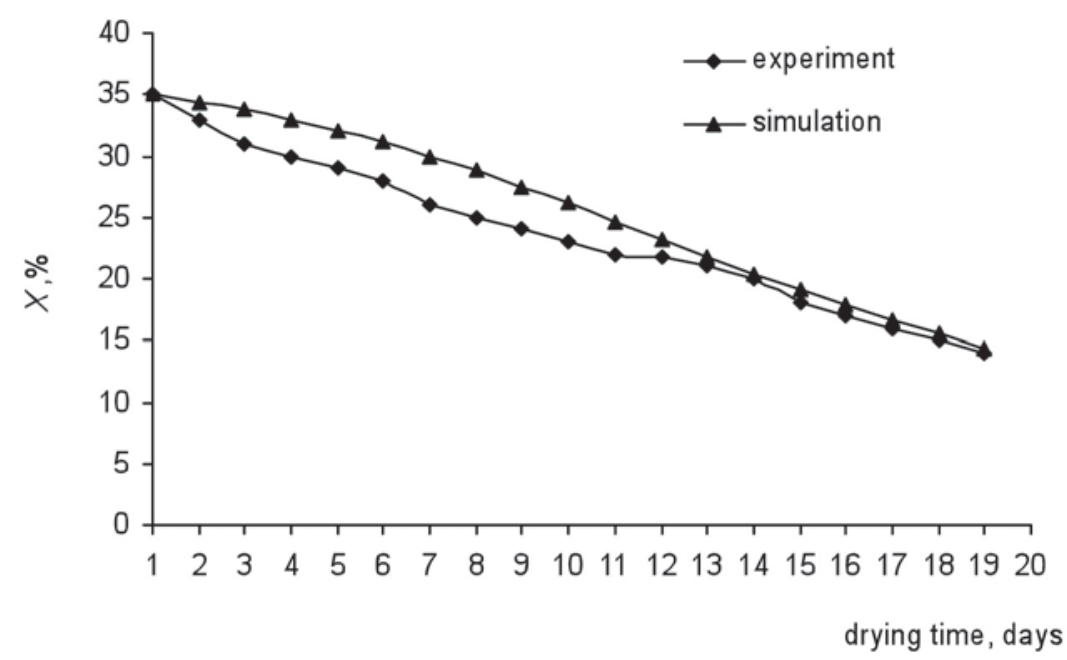

Fig.8. Comparison of measured and computed moisture content of solar drying for $27 \mathrm{~mm}$ of thuya in Essaouira.

\section{CONCLUSION}

This study shows that it is possible to describe the thermal behavior of a wood solar dryer by using a simplified modeling. The mathematical model, which is based on actual climate data and which takes into account the main phenomena of heat and mass transfer, allows to specify the dryer humidity and temperatures (air and walls) and the wood temperature and moisture contents during the period of drying.

The temperatures recorded inside the dryer are always higher than those of the external air which shows the importance of solar drying compared to open air drying.

The comparative study gives a reasonable agreement between computed and experimental values of the wood moisture content of drying cycles performed on two dryers located in two different sites.

\section{REFERENCES}

Awadalla, H.S.F.; El-Dib, A.F.; Mohamad, M.A.; Reuss, M.; Hussein, H.M.S. 2004. Mathematical modelling and experimental verifications of wood drying. Energy Conversion and Management 45:197-207.

Bentayeb, F.; Bekkioui, N.; Zeghmati, B. 2008. Modelling and simulation of a wood solar dryer in a Moroccan climate. Renewable Energy 33: 501-506.

Chen, P.Y.S.; Helton, C.E. 1989. Design and evaluation of a low-cost solar kiln. Forest Products Journal 39 (1): 19-22. 
Chrusciel, L.; Mougel, E.; Zoulalian, A.; Meunier, T. 1999. Characterisation of water transfer in a low temperature convective wood drier: influence of the operating parameters on the mass transfer coefficient. Holz als Roh- und Werkstoff 57: 439-445.

El kannafi, A. 2002. Etude de la faisabilité du séchage solaire du bois de Thuya dans la ville d'Essaouira. Mémoire de 3ème cycle. Ecole Nationale Forestière d'Ingénieurs.

Haque, M.N.; Langrish, T.A.G. 2003. Mathematical modelling of solar kilns for drying timber: Model developement and validation. Drying Technology 21(3):457-477.

Helwa, N. H.; Khater, H. A.; Enayet, M. N.; Hashish, M.I. 2004. Experimental Evaluation of Solar Kiln for Drying Wood. Drying Technology 22(4):703-717.

Khater, H. A.; Helwa, N. H.; Enayet, M. N.; Hashish, M.I. 2004. Optimisation of Solar Kiln for Drying Wood. Drying Technology 22(4):677-701.

Nougier, J.P. 1989. Méthodes de calcul numérique. 3ème édition: Paris, Milan, Barcelone, Mexico. Masson.

Reuss, M.; Benkert, S.T.; Aeberhand, A.; Martina, P.; Raush, G.; Rentzell, B.V.; Sogar, N. 1997. Modelling and experimental investigation of a pilot plant for solar wood drying. Solar Energy 59(46):259-270

Simpson, W.; TenWolde, A. 1999. Physical properties and moisture relations of wood. Wood Handbook, Wood as an Engineering Material. Forest Products Laboratory.United States Department of Agriculture, Madison.

Taylor, K.J.; Weir, A.D. 1985. Simulation of solar timber dryer. Solar Energy 34 (3): 249-255.

Youssefi, M. 1997. Le séchage du bois au Maroc, construction et expérimentation d'un séchoir solaire pilote. Mémoire de 3ème cycle. IVA Hassan II, Rabat.

\section{Appendix: Climatic Data}

The solar data and the climatic variables relating to the year 2002 were provided to us by the Laboratory of Solar energy of Mohammed V-Agdal University, Rabat. These data consist of:

The direct solar radiation on a plane perpendicular to the solar rays: $I_{n}$.

The total solar radiation on a horizontal plane: I

The ambient temperature: Tex

The relative humidity: $\mathrm{RH} \%$

These data were recorded every six minutes and the average of ten values gives the hourly values. The total radiation $I_{\beta}$ on a plane inclined $\beta$ degrees from the horizontal plane was determined by the following formula:

$$
I_{\beta}=I_{n} \cos \theta+\frac{1}{2} I_{d}(1+\cos \beta)+\frac{1}{2} \rho(1-\cos \beta),
$$


where $\theta$ is the angle of incidence between direct radiation and the inclined plane, and $\mathrm{I}_{d}$ and $\rho$ are defined below. The angle $\theta$ is given by:

$$
\cos \theta=\sin \delta \sin (\varphi-\beta)+\cos \delta \cos (\varphi-\beta) \cos \omega
$$

where $\delta$ is the declination of the sun, that is, the angle between the rays of the sun and the plane of the earth's equator, and is given by:

$$
\delta=23,45 \sin \frac{360}{365}(j+284)
$$

where:

$\mathrm{j}$ is day of the year,

$\varphi$ is the latitude, and $\omega$ is the hour angle of the sun:

$\omega=15\left(T_{\text {solar }}-12\right)$, where $T_{\text {solar }}$ is the solar time.

$I_{d}$ is the diffuse radiation of a horizontal plane given by: $\quad I=I_{d}+I_{n} \sin h$

where $h$ represents the height of the sun given by:

$$
\sin h=\sin \varphi \sin \delta+\cos \varphi \cos \delta \cos \omega
$$

Finally, $\rho$ is the reflexion coefficient of the ground called albedo of the ground. It varies according to the nature of the ground, its average value is: $\rho=0.25$.

\section{Nomenclature}

$C_{a}$ : specific heat of dry air, $\mathrm{J} \cdot \mathrm{kg}^{-1} \cdot \mathrm{K}^{-1}$

$C_{b}$ : specific heat of dry wood, $\mathrm{J}^{\mathrm{kg}} \mathrm{kg}^{-1} \cdot \mathrm{K}^{-1}$

$C_{e}$ : specific heat of liquid water, $\mathrm{J} \cdot \mathrm{kg}^{-1} \cdot \mathrm{K}^{-1}$

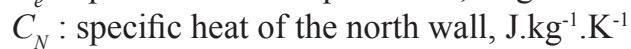

$C_{v i}:$ specific heat of the glass vi, $\mathrm{J}_{\mathrm{kg}} \mathrm{kg}^{-1} \cdot \mathrm{K}^{-1}$

$e$ : wood thickness, $\mathrm{m}$

$F_{b N}$ : geometrical factor between wood stack and north wall

$F_{b v}$ : geometrical factor between wood stack and glass

$F_{i G}$ : geometrical factor between air and glass

$G$ : mass flow rate of dry air, kg.s ${ }^{-1}$

$G_{v i}$ : solar irradiance received by the glass vi, W. $\mathrm{m}^{-2}$

$H R$ : relative humidity of air, $\%$

$h_{p}:$ height of the wood stack, $\mathrm{m}$ 
$K_{e}$ : global mass transfer coefficient wood water - gas water, $\mathrm{kg} \cdot \mathrm{m}^{-2} \cdot \mathrm{s}^{-1}$

$K_{v i}$ : convective heat transfer coefficient between air and glass vi, $\mathrm{W} \cdot \mathrm{m}^{-2} \cdot \mathrm{K}^{-1}$

$K_{b}^{*}$ : convective heat transfer coefficient between wood and air, $\mathrm{W} \cdot \mathrm{m}^{-2} \cdot \mathrm{K}^{-1}$

$K_{N}^{*}$ : convective heat transfer coefficient between north wall and air, $\mathrm{W} \cdot \mathrm{m}^{-2} \cdot \mathrm{K}^{-1}$

$K_{v i}^{*}$ : convective heat transfer coefficient between glass and air, $\mathrm{W} \cdot \mathrm{m}^{-2} \cdot \mathrm{K}^{-1}$

$k_{v i}$ : heat transfer coefficient between glass and ambient air, $\mathrm{W} \cdot \mathrm{m}^{-2} \cdot \mathrm{K}^{-1}$

$k_{N}$ : heat transfer coefficient between north wall and ambient air, $\mathrm{W} \cdot \mathrm{m}^{-2} \cdot \mathrm{K}^{-1}$

$L_{p}$ : length of the wood stack, $\mathrm{m}$

$l_{p}^{p}$ : width of the wood stack, $\mathrm{m}$

$\stackrel{p}{M_{0}}$ : oven dry mass of the wood, $\mathrm{kg}$

$M:$ total mass of the wood, $\mathrm{kg}$

$m_{a}:$ mass of dry air, $\mathrm{kg}$

$m_{N}:$ mass of the north wall, $\mathrm{kg}$

$m_{v i}:$ mass of the glass vi, $\mathrm{kg}$

$S_{b}$ : exchanges surface between stack and air, $\mathrm{m}^{2}$

$S_{N}$ : area of the north wall, $\mathrm{m}^{2}$

$S_{v i}:$ area of the glass vi, $\mathrm{m}^{2}$

$T_{a}$ : air temperature, $\mathrm{K}$

$T_{\mathrm{b}}$ : wood temperature, $\mathrm{K}$

$T_{e x}$ : ambient air temperature, $\mathrm{K}$

$T_{v i}:$ glass temperature, $\mathrm{K}$

$V$ : volume of the dryer, $\mathrm{m}^{3}$

$V_{b}$ : volume of the wood in the dryer, $\mathrm{m}^{3}$

$W_{E}$ : air moisture content at the entrance of the dryer, ${\mathrm{kg} . \mathrm{kg}^{-1}}^{-1}$

$W_{S}:$ air moisture content inside the dryer, $\mathrm{kg} \mathrm{kg}^{-1}$

$X:$ moisture content of wood, $\mathrm{kg} \cdot \mathrm{kg}^{-1}$

$X_{0}$ : initial moisture content of wood, $\mathrm{kg} \cdot \mathrm{kg}^{-1}$

$X_{P S F}$ : moisture content of wood at F.S. P, $\mathrm{kg} \mathrm{kg}^{-1}$

$X^{*}$ : equilibrium moisture content of wood, $\mathrm{kg} \cdot \mathrm{kg}^{-1}$

$\alpha_{v i}:$ absorptance of the glass, N.D

$\alpha_{N}$ : absorptance of the north wall, N.D

$\varepsilon_{b}$ : emissivity of wood, N.D

$\varepsilon_{N}:$ emissivity of the northern wall, N.D

$\varepsilon_{v}:$ emissivity of the glass, N.D

$\rho_{\mathrm{g}}:$ gas density

$\rho_{0}$ : basic density of wood, $\mathrm{kg} \cdot \mathrm{m}^{-3}$

$v:$ air velocity, $\mathrm{m} \cdot \mathrm{s}^{-1}$

$\sigma:$ Stefan -Boltzmann constant $\left(5,67 \mathrm{~W} \cdot \mathrm{m}^{-2} \cdot \mathrm{K}^{-4}\right)$

$\Lambda$ : latent heat of vaporization, $J . \mathrm{kg}^{-1}$ 
